\title{
O PROGRAMA PARANÁ FALA INGLÊS EM \\ UMA UNIVERSIDADE PÚBLICA PARANAENSE: A VISÃO DE SEUS PARTICIPANTES
}

\section{The "Paraná speaks English" program in a public university in Paraná: Participants' perspective}

Flávia Bissi de Oliveira Programa de Pós-Graduação em Letras

Universidade Estadual de Maringá

flaviabissi@hotmail.com https://orcid.org/0000-0001-6231-7642

Lara Beatriz Zanesco

Universidade Estadual de Maringá larazanesco@gmail.com https://orcid.org/0000-0002-8251-4632

Luciana Cabrini Simões Calvo Programa de Pós-graduação em Letras

Universidade Estadual de Maringá cabrinisimoes@gmail.com https://orcid.org/0000-0001-8145-0588

\begin{abstract}
RESUMO: Este artigo analisa o Programa Paraná Fala Inglês (PFI), na sua segunda fase, em uma universidade pública do norte-paranaense, sob a perspectiva de seus participantes (coordenadoras e professores). Assim, ele i) examina a visão dos participantes sobre o programa no processo de internacionalização da universidade; ii) analisa suas expectativas iniciais a respeito do PFI e como estas foram sendo (ou não) concretizadas; iii) investiga os pontos positivos e lacunares do programa, de acordo com a perspectiva dos integrantes. Os dados foram gerados por meio da aplicação de questionários dissertativos e a discussão realizada se embasa em trabalhos acerca da internacionalização (JORDÃO; MARTINEZ, 2015; STALLIVIERI,2002; MARRARA; RODRIGUES, 2016 , dentre outros). Os resultados indicam que o programa tem contribuído com a internacionalização acadêmica por meio da oferta de cursos e de editais de mobilidade, além de ser um contexto relevante e diferenciado para a formação docente continuada. Apesar de alguns pontos lacunares apontados, os aspectos positivos se sobressaem e as expectati-
\end{abstract}

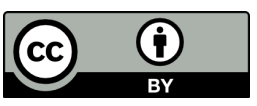


vas de todos os participantes se concretizaram ou foram ressignificadas. PALAVRAS-CHAVE: Paraná Fala Inglês; Coordenadoras e professores; Instituição de Ensino Superior.

ABSTRACT: This article analyzes the second phase of the Paraná Speaks English Program (PFI) in a public university in north Paraná, from the perspective of its participants (coordinators and teachers). Thus, it i) examines the participants' view of the program in the internationalization process of the university; ii) analyzes their initial expectations about PFI and how they were (or were not) realized; iii) investigates the program's positive and negative points, according to the participants. The data were generated through the application of questionnaires and the discussion is based on studies about internationalization (JORDÃO; MARTINEZ, 2015; STALLIVIERI,2002; MARRARA; RODRIGUES, 2016, among others). The results indicate that the program has contributed to academic internationalization by offering courses and mobility opportunities, resides being a different and interesting context for continuous teacher education. Despite some gaps, the positive aspects stand out and the expectations of all participants have been realized or have been re-signified. KEY WORDS: Paraná Speaks English; Coordinators and teachers; Higher education institution.

\section{INTRODUÇÃO}

As políticas de internacionalização do ensino superior têm sido tendências desde o final do século XX em universidades por todo o mundo. No caso do Brasil, como mostra o estudo de Rodrigues e Marrara (2009), a internacionalização representa uma estratégia para inserir as instituições no contexto internacional de modo a aprimorar o ensino e a pesquisa assim como, em nosso ponto de vista, a extensão. Para os autores, o uso de idiomas estrangeiros, dentre outras estratégias, são recursos indispensáveis nesse processo.

Sobre a internacionalização, Knight (2008 citado por BAUMVOL; SARMENTO, 2016, p. 67) menciona que a popularidade do termo na área da educação se deu na década de 80, pois "seu uso já era comum nas áreas de Ciência Política e de relações intergovernamentais". Para Baumvol e Sarmento (2016, p. 67), “a internacionalização se mostra como elemento definidor e essencial para a configuração do ensino superior no século XXI, emergindo como um processo de rápida evolução”. Dentre as estratégias utilizadas pelas IES, as autoras destacam a cooperação e os projetos internacionais, os 
acordos e redes institucionais, os diferentes tipos de mobilidade acadêmica e as dimensões internacionais e interculturais do processo de ensino/aprendizagem, currículo e pesquisa.

Além desses aspectos, também pontuamos questões que envolvem o desenvolvimento da proficiência linguística da comunidade acadêmica em vários idiomas, por meio do planejamento e fortalecimento de políticas linguísticas. Assim, lançamos nosso olhar, neste artigo, para a segunda fase do Programa Paraná Fala Idiomas-Inglês, da Superintendência de Ciência, Tecnologia e Ensino Superior (SETI). Tal programa foi implementado no segundo semestre de 2014 (primeira fase) nas sete instituições de ensino superior do Paraná (UEL, UEM, UEPG, UNIOESTE, UNICENTRO, UENP e UNESPAR). Segundo Rios (2021), a primeira etapa durou 22 meses e teve como foco cursos preparatórios para exames de proficiência, como o TOEFL ITP. Segundo a autora, "tal escolha foi balizada no contexto do programa em nível federal chamado "Ciência sem Fronteiras", que exigia a comprovação do nível linguístico dos alunos por meio de testes de certificação internacional” (p. 21).

O foco da pesquisa aqui relatada é a segunda etapa de realização do PFI, a qual ocorreu entre 2017 e 2019, em uma universidade pública do norte-paranaense. Esta fase:

lançada no segundo semestre de 2017, partiu do princípio de que é preciso ir além da preparação da comunidade universitária para a realização de testes de proficiência e ir ao encontro das reais necessidades dos contextos educacionais para dar o devido apoio ao processo de internacionalização das IES, ação que se reafirmou frente a um momento nacional histórico de valorização da internacionalização e necessidade de desenvolvimento de planos estratégicos de internacionalização que incluam as políticas linguísticas. (RIOS, 2021, p. 22-3)

De acordo com informações disponibilizadas na página institucional do PFI da universidade em questão, este tem como objetivo promover a internacionalização das Instituições de Ensino Superior (IES) do Estado, por meio da oferta de diversas opções de cursos de língua inglesa e francesa voltados para a comunidade acadêmica das universidades estaduais. Tais cursos, segundo a página, visam capacitar "linguisticamente seus participantes para atividades de internacionalização".

Com base nessa breve contextualização, investigamos a visão dos envolvidos no PFI a respeito deste, contribuindo para que se tenha uma visão local do seu funcionamento e do seu papel para a internacionalização acadêmica. Dessa forma, o objetivo da pesquisa realizada foi o de analisar a visão de coordenadoras e professores do PFI de uma instituição pública paranaense a respeito do mencionado projeto, em sua segunda fase de execução. De modo específico, ela examina a visão dos participantes sobre o PFI Revista X, v. 16, n. 6, p. 1510-1527, 2021. 
no processo de internacionalização da universidade, suas expectativas iniciais a respeito deste e como estas estão sendo (ou não) concretizadas, além dos pontos positivos e lacunares, de acordo com a perspectiva desses integrantes.

Para discussão teórica, tomou-se como base os estudos de Jordão e Martinez (2006); Rodrigues e Marrara (2009); Romão (2011); Baumvol e Sarmento (2016); dentre outros, sobre o processo de internacionalização nas Instituições de Ensino Superior (IES).

Este estudo é de natureza qualitativa, configurando-se como estudo de caso, visto que analisaremos uma unidade bastante específica (PFI em uma Instituição pública no norte do Paraná). Sobre o estudo de caso como metodologia de pesquisa, Andre (1995) assevera que:

o estudo de caso enfatiza o conhecimento do particular. $\mathrm{O}$ interesse do pesquisador ao selecionar uma determinada unidade é compreendêla como uma unidade. Isso não impede, no entanto, que ele esteja atento ao seu contexto e às suas inter-relações como um todo orgânico, e à sua dinâmica como um processo uma unidade em ação (ANDRE, 1995, p. 31).

Para geração dos dados, aplicou-se um questionário de cunho dissertativo aos professores e às coordenadoras do PFI, no ano de 2018, tendo em vista os objetivos propostos.

Frente a essa contextualização, o presente artigo está organizado da seguinte forma: a princípio faremos uma breve apresentação teórica sobre a internacionalização; então, contextualizaremos o programa Paraná Fala Inglês, foco desta pesquisa; logo, analisaremos os dados gerados com seus resultados e, por fim, traremos as considerações finais.

\section{A INTERNACIONALIZAÇÃO}

A insaciável busca pelo conhecimento e por descobertas é o que sustenta o meio acadêmico e científico. Desde as primeiras universidades, surgidas durante a Idade Média, havia uma proposta de análise da "universalidade do conhecimento e de todo o saber" (STALLIVIERI, 2002, p. 1). Conforme a autora, o deslocamento de estudantes de e para diferentes nações em vista de aprimoramento cognitivo já marcava o caráter internacional das universidades da época, contribuindo para o crescimento e o prestígio mundial destas.

Desde as últimas décadas do século $\mathrm{XX}$, o termo internacionalização tem sido destacado no âmbito do Ensino Superior. Isso se deu, segundo Romão (2011), com a 
aceleração da globalização nos setores econômicos e financeiros, e por meio de sua manutenção por grupos do capital estrangeiro. $O$ pesquisador afirma que isso justificase devido à "necessidade de padronização da qualidade expressa nos diplomas, para a consolidação de blocos supranacionais, nos quais possa ocorrer uma mais fluida circulação de profissionais, de pesquisadores, de professores e de estudantes" (2011, p. 60). Nesse sentido, Stallivieri (2002, p.3) afirma que é preciso internacionalizar as IES para que estas se nivelam e compitam igualmente às melhores universidades dos âmbitos nacional e internacional. Em relação a essa última proposição, Jordão e Martinez (2015, p. 7273) ponderam que, quando autores referem-se às universidades estrangeiras como as melhores e aquelas que devem ser alcançadas, inferioriza-se a educação das IES nacionais, propagando uma concepção de desigualdade e uma visão de colônia e metrópole.

Ademais, Marrara e Rodrigues (2009, p. 123) apontam que a internacionalização das universidades brasileiras deve, primordialmente, ser uma estratégia de inserção das academias no cenário internacional, em vista do aprimoramento do ensino e da pesquisa. Para isso, os autores destacam que este processo pode se dar de duas formas, a internacionalização ativa e a passiva. Na primeira, a IES recebe recursos humanos e pesquisas internacionais; na segunda, os membros da IES atuam em IES estrangeiras e publicam produções nacionais em veículos de divulgação externos, como afirmam os autores.

A ocorrência de uma ou outra estratégia depende, de acordo com Castro e Neto (2012, p. 77), da existência ou não de políticas governamentais que fomentem a mobilidade estudantil e que capacitem o acolhimento de estudantes estrangeiros.

Além disso, outras atividades de internacionalização que podem ser desenvolvidas no próprio contexto de aprendizagem e atuação da comunidade acadêmica, no sentido de incluir e contemplar um número maior de participantes, também ganham destaque (por exemplo, a internacionalização do currículo; atividades de intercâmbio virtual de aprendizagem; dentre outras), como iniciativas de "Internacionalização em Casa" (e.g. BEELEN; JONES, 2015).

De qualquer forma, durante a conferência sobre Educação Superior no século XXI (1998), ficou evidenciado que a internacionalização deveria permear os planos de estudo e os processos de ensino e aprendizagem enquanto tema primordial nas agendas dos governos, como esclarecem Castro e Neto (2012). A UNESCO ${ }^{1}$ defende que, por meio da internacionalização, é possível a promoção de justiça e igualdade social, além de preconizar que esse processo deve ir além da cooperação internacional entre os países

\footnotetext{
${ }^{1}$ UNESCO - Organização das Nações Unidas para a Educação, a Ciência e a Cultura.
} 
que buscam alcançar um objetivo comum em conjunto, mas deve, como mostram os estudiosos, "inserir uma dimensão internacional ou intercultural em todos os aspectos da educação e da pesquisa" (Castro e Neto, 2012, p. 74).

No cenário nacional, em 2011, foi criado o programa federal de mobilidade acadêmica, o Ciência sem Fronteiras (CsF). Passoni (2018, p. 34) o destaca "como um marco em relação às políticas linguísticas, sendo que demandas relativas à proficiência em inglês emergiram deste Programa [...]”, a partir do qual surgiu o Inglês sem Fronteiras. Para a autora, esses programas foram relevantes para incitar a internacionalização acadêmica brasileira.

Diante do despreparo linguístico na língua inglesa dos estudantes, evidenciado no Ciência sem Fronteiras, dois aspectos são focalizados, de acordo com Jordão e Martinez (2015). Primeiro, as autoras afirmam a necessidade de uma reflexão quanto ao ensino de língua inglesa na educação básica no nosso país, tanto na rede pública quanto na privada. Segundo, elas julgam necessário analisar como o sistema educacional brasileiro permite aos alunos alcançar o nível de inglês exigido por programas de mobilidade acadêmica.

$\mathrm{O}$ programa $\mathrm{CsF}$ deu origem ao Inglês sem Fronteiras, no intuito de sanar a lacuna linguística dos acadêmicos brasileiros e, assim, instrumentalizá-los para os programas de mobilidade.

Além desses programas, em nível nacional, que contribuem para o processo de internacionalização acadêmica, foi criado, em âmbito estadual, o programa Paraná Fala Idiomas-Inglês, o qual tem se configurado com uma iniciativa de política linguística estadual (RIOS; NOVELLI; CALVO, 2021).

De acordo com o trabalho de Marson e Borges (2015), pesquisadoras que analisaram os resultados parciais da primeira etapa do PFI na UEPG, o programa conseguiu concretizar seus objetivos quanto à capacitação dos alunos para o teste TOEFL iBT e a aplicação deste aos participantes do programa. As autoras afirmam que o PFI foi um ponto inicial para a internacionalização da IES, uma vez que "possibilita[ou] aos candidatos o desenvolvimento das habilidades linguístico-comunicativas na língua inglesa para que possam fazer o teste do TOEFL iBT e almejar o ingresso em universidades estrangeiras." (MARSON; BORGES, 2015, p. 87)

A segunda etapa do PFI iniciou em junho de 2017. Nessa fase, conforme já pontuado, foram ofertadas diversas opções de cursos de língua inglesa para alunos de graduação, pós-graduação, docentes e agentes universitários das universidades estaduais. Lançada em 2021, a coletânea "Paraná Fala Idiomas- Inglês: pesquisas, práticas e desafios de uma política linguística de Estado" (RIOS, NOVELLI, CALVO, 2021) reúne artigos 
de professores, acadêmicos e pesquisadores envolvidos na investigação da primeira ou segunda fase do programa.

O PFI, quando do envio deste artigo para publicação, estava em sua terceira fase de execução. Então, acreditamos que trabalhos que lançam olhares para a trajetória do programa, para seus desdobramentos e impactos são relevantes para uma melhor compreensão dessa política linguística estadual.

\section{GERAÇÃO E ANÁLISE DOS DADOS}

Conforme indicado, o contexto investigado refere-se ao PFI de uma universidade pública do norte paranaense, em sua segunda edição. Na época da pesquisa, todos os coordenadores e professores foram convidados a participarem: eram, na época, duas coordenadoras e três professores, que atuaram no programa no segundo semestre de 2018 , época da geração dos dados. Todos eles aceitaram participar da pesquisa, respondendo ao questionário enviado. $\mathrm{O}$ convite para participar desse estudo foi realizado por e-mail por uma das pesquisadoras, Flávia Bissi de Oliveira, no dia $1^{\circ}$ de julho de 2018. A mensagem enviada foi:

"Meu nome é Flávia Bissi de Oliveira, sou graduanda do terceiro ano do curso de Letras - Português/Inglês, da UEM. Em conjunto com minha colega de turma, a acadêmica Lara Beatriz Zanesco, e sob a orientação das professoras Luciana Cabrini Simões Calvo e Érica Fernandes Alves (DLM), estamos desenvolvendo o Projeto de Iniciação Científica intitulado "O Programa Paraná Fala Inglês em uma universidade pública paranaense: a visão de seus participantes". Para a realização de nossa pesquisa, gostaríamos de convidá-los a responder o questionário em anexo. Sua participação é opcional, entretanto, de extrema importância para o desenvolvimento de nossa investigação. Sendo assim, contamos com a sua valiosa colaboração.”

Em conjunto com a mensagem, também foi disponibilizado o questionário para que os participantes pudessem responder. As perguntas foram elaboradas e anexadas no processador de texto Microsoft Word. No documento do questionário havia uma apresentação da pesquisa, a fim de explicá-la e defender o interesse e as decisões dos que estão envolvidos no estudo. A introdução do questionário em anexo foi: 


\section{"Prezado/a professor/a,}

Este questionário faz parte da pesquisa de iniciação científica “O Programa Paraná Fala Inglês em uma universidade pública paranaense: a visão de seus participantes”, sob orientação das professoras Luciana Cabrini Simões Calvo e Érica Fernandes Alves, que tem como objetivo analisar a visão de coordenadores e professores do programa Paraná Fala Inglês de uma instituição pública paranaense a respeito do referido programa. Caso aceite participar da pesquisa, leia com atenção os seguintes pontos:

a. você pode recusar-se ou deixar de participar da pesquisa a qualquer momento sem a necessidade de apresentar justificativas para isso;

b. sua identidade será mantida em sigilo;

c. as informações aqui apresentadas serão utilizadas apenas para os fins desta pesquisa;

d. caso você queira, poderá ser informado(a) de todos os resultados obtidos com a pesquisa, independentemente do fato de mudar seu consentimento em participar da pesquisa.

Agradecemos sua preciosa colaboração!”

Todos os participantes do programa que foram convidados a participar da pesquisa responderam ao questionário. Ademais, os docentes escolheram pseudônimos para si, assim, dentre os professores, participaram da pesquisa Wali, 26 anos, X, 28 anos, e Ana, 30 anos (esta não apresentou um pseudônimo e, para fins desta pesquisa, optamos por nomeá-la Ana). As coordenadoras escolheram os pseudônimos Laura, 40 anos, e Lia, 36 anos.

A partir dos dados obtidos por meio da aplicação de um questionário de cunho dissertativo, aos professores e às coordenadoras, ao qual todos responderam, obtemos os seguintes perfis dos participantes: Wali atuava há 6 anos como professor de língua inglesa e estava há 2 meses no PFI; X lecionava há 5 anos e participava há 1 ano no programa; Ana atuava como docente há 10 anos e integrava o programa há 1 ano e 2 meses; a coordenadora Laura estava na IES em questão há 6 anos e, há 1 ano e 9 meses, no PFI; e Lia trabalhava na instituição há 2 anos e coordenava o programa há 1 ano e 4 meses.

Uma vez que os questionários foram respondidos, para análise dos dados, elaboramos duas tabelas, uma para os professores e outra para as coordenadoras. Nelas, elencamos, a partir de suas respostas, os pontos e as visões semelhantes e específicos, levantados/as por cada participante nos questionários. A partir da tabela comparativa 
elaborada, analisamos cada questão do questionário, trazendo a visão das coordenadoras e professores, como apresentado a seguir.

\section{ANÁLISE E DISCUSSÃO DOS DADOS}

Como vimos até aqui, o programa Paraná Fala Inglês visa capacitar linguísticocomunicativamente alunos de graduação, pós-graduação, professores e agentes universitários das Instituições de Ensino Superior do Paraná, tendo em vista a internacionalização destas. A primeira fase do programa teve início no ano de 2014, sendo que este artigo teve como foco a segunda fase do PFI (a partir de 2017), em uma universidade pública do norte-paranaense. Para isso, buscamos analisar a visão daqueles que atuaram nesse contexto: os professores e as coordenadoras, com um questionário endereçado a eles em 2018.

O primeiro ponto sobre o qual lançaremos olhar são as motivações para participar do PFI.

\section{Motivações para participar do PFI}

As coordenadoras colocam, como ponto comum na decisão de integrar o programa, a viabilidade de poder contribuir com a formação linguística da comunidade acadêmica visando a internacionalização, para a qual é necessária a implantação de um programa como o PFI dentro da IES. Laura menciona que sua decisão também foi tomada a partir de um convite de um colega de trabalho. Já Lia diz que a possibilidade de expandir e de colocar em prática seus conhecimentos de formação docente em língua inglesa, a partir da troca de experiências entre os integrantes do programa, também foi uma das motivações para sua participação no PFI.

Os professores, de modo geral, mencionaram o ensino da língua inglesa em uma instituição pública como um dos principais motivos para participarem do programa. Além disso, o valor da bolsa chamou a atenção destes. Outros pontos destacados por Wali foram: a carga horária ${ }^{2}$ que viabiliza uma melhor preparação das aulas; a flexibilidade oferecida aos professores nas maneiras de ministrar as aulas e, por fim, o número reduzido

\footnotetext{
${ }^{2}$ Em um dos editais consultados do PFI da IES em questão, no ano de 2018, a carga horária do profissional era dividida da seguinte forma: "Cada bolsista deverá dedicar 40 horas semanais ao PFI para ministrar aulas a 03 turmas ( $4 \mathrm{~h} /$ semana por turma - total $12 \mathrm{~h}$ ), 12 horas horas para preparação das aulas, 08 horas para desenvolvimento de pesquisa, 04 horas para formação pedagógica e metodológica e 04 horas para atendimento aos alunos".
} 
de alunos em sala de aula. Ana afirma que também decidiu participar devido a IES ser renomada. Ademais, X menciona que foi incentivado por seus colegas.

\section{Expectativas em relação ao $\mathrm{PFI}$}

$\mathrm{O}$ segundo aspecto a ser discutido refere-se às expectativas iniciais dos participantes acerca do PFI e como estas foram (ou não) concretizadas. De acordo com a coordenadora Laura, no início do programa, não estava tão animada devido ao nível de exigência das atividades e demandas, além da necessidade de se apropriar de temas voltados para internacionalização. Após experienciar tanto a função de orientadora pedagógica quanto, na época da geração dos dados, de coordenadora institucional, ela tem uma nova visão sobre o PFI. Assim, a coordenadora passou a ver "o programa como um grande potencial para futuras parcerias com universidades estrangeiras em termos de pesquisa e mobilidade acadêmica" (Laura).

Por sua vez, Lia tinha boas expectativas inicialmente, as quais se concretizaram, em relação à prática didática-pedagógica e à aprendizagem docente. Para ela, suas expectativas se reconfiguraram à medida que precisou desenvolver suas habilidades de trabalho em equipe. A coordenadora também esperava aprender bastante em relação à prática pedagógica e docente, "mas não esperava que iria desenvolver tanto a habilidade do trabalho em grupo como tenho desenvolvido". Isso se deu, pois, de acordo com Lia, ao longo de sua atuação, ela se deu conta "da grandiosidade e da importância do programa", o que lhe fez perceber que o trabalho em equipe era essencial para o PFI. Dessa forma, como se pode notar, as expectativas iniciais das coordenadoras foram, cada uma de seu modo, ressignificadas.

Já em relação aos professores, eles pontuaram de forma objetiva suas expectativas iniciais em relação ao programa. Uma expectativa inicial comum aos professores referiase à distribuição da carga horária que lhes permite ter mais tempo para preparação das aulas, o que se concretizou para todos. A professora Ana relata que, desde o início, tinha expectativas grandiosas em relação ao PFI uma vez que ela atuaria em uma universidade de renome e isso "sempre trouxe uma certeza de que eu estaria realizando o meu sonho profissional e, quando eu entrei no programa, eu me realizei mais ainda, porque eu percebi que era algo muito grandioso, muito significativo". Ainda assim, a docente afirma que suas expectativas se reconfiguravam a cada semestre, "porque a cada semestre é um novo desafio".

O professor X explica que também esperava aprimorar seus conhecimentos acerca do ensino de idiomas, o que de fato ocorreu. Além disso, ele se deparou com um sistema Revista X, v. 16, n. 6, p. 1510-1527, 2021. 
de interatividade entre os professores e orientadores no planejamento das aulas o que para ele é um momento de extrema importância, "pois, permite que eu possa reavaliar a minha própria aula, além de oferecer um "feedback" sobre a minha atuação enquanto professor". O professor Wali, de forma bastante sucinta, explicou como suas expectativas se concretizaram: "As condições de trabalho são ótimas, o salário é exatamente o esperado, há supervisão eficiente por parte das coordenadoras do projeto e a identificação com o contexto foi bastante satisfatória para mim".

A partir das considerações feitas pelas coordenadoras e professores, percebemos que as expectativas em relação ao programa eram altas e positivas, exceto para Laura. No entanto, até mesmo para ela, as expectativas se reconfiguraram, também de forma positiva, e vem se concretizando. Isto posto, as expectativas se mantiveram (Wali)/, se concretizaram $(\mathrm{X})$ e se reconfiguram constante e positivamente (Ana).

\section{O PFI e a internacionalização da universidade}

A internacionalização das universidades brasileiras, como colocam Marrara e Rodrigues (2009), insere as IES no cenário internacional, tendo em vista o desenvolvimento educacional e científico destas. Para que isso aconteça, é necessário que a comunidade acadêmica tenha "desenvolvimento pessoal, formação acadêmica e proficiência linguístico-comunicativa na língua estrangeira para conseguir uma pontuação mínima em testes internacionais requeridos pelas universidades estrangeiras e setores privados" (MARSON; BORGES, 2015, p. 75). Indo além, complementamos que o desenvolvimento da proficiência linguística em vários idiomas (incluindo o português como língua estrangeira) é importante para a participação da comunidade em várias iniciativas de internacionalização, sendo essas no próprio campus ou em demais contextos.

Isto posto, outro aspecto discutido foi: o PFI e a internacionalização da universidade. O Paraná Fala Inglês atua na capacitação linguística de seus participantes de forma a prepará-los para o processo de internacionalização e oferecendo-lhes editais para a mobilidade acadêmica ${ }^{3}$, como afirmam as coordenadoras Lia e Laura. Outro ponto

\footnotetext{
${ }^{3}$ Em 2018, o PFI abriu edital para mobilidade internacional ao Canadá. Alunos do programa das sete universidades estaduais foram contemplados e as coordenadoras institucionais ou pedagógicas das sete IES também participaram de atividades no país. Mais recentemente, em 2021, alunos do Paraná Fala Inglês e Francês participaram de uma oportunidade de Mobilidade Virtual 'Jumelage' com a Université du Québec à Montreal.
} 
destacado por Lia é a importância do programa para o desenvolvimento da competência cultural dos alunos.

Os professores, tal qual as coordenadoras, pontuaram a importância do PFI para o desenvolvimento linguístico da comunidade acadêmica, destacando a relevância da oferta de aulas temáticas, com conteúdos específicos a diferentes áreas do conhecimento, além da produção constante de gêneros textuais acadêmicos: o PFI também impulsiona a internacionalização "preparando os alunos com aulas temáticas relevantes em cursos específicos; possibilitando a criação de uma ligação entre os profissionais ligados à academia e o idioma (no caso da língua inglesa, esta necessidade é ainda mais visível)" (prof. Wali)

Ainda, chamaram atenção para a oferta de bolsas de estudo de mobilidade internacional ofertadas pelo PFI a seus participantes. Além disso, Wali ressalta o papel do programa enquanto uma ponte entre a língua inglesa e a comunidade acadêmica, preparando esta para um mundo globalizado.

\section{Participação em um programa com vistas à internacionalização acadêmica}

Em seguida, foi analisada a participação em um programa com vistas à internacionalização acadêmica. Lia e Laura relataram que aprimoraram seus conhecimentos sobre a internacionalização ao coordenarem o programa. Elas ainda pontuaram que o PFI alavanca a universidade no cenário internacional, uma vez que capacita linguísticamente a comunidade acadêmica a produzirem em língua estrangeira. Laura lançou o olhar para a responsabilidade e dedicação exigida pelo programa, além do grande desafio de divulgar os cursos e de conscientizar a comunidade acerca da necessidade do programa no aprimoramento linguístico da academia e, consequentemente, da permanência dos alunos no PFI.

Para Lia, coordenar o programa também foi gratificante, uma vez que ela vê, na internacionalização, um meio de trocar experiências científicas, políticas e culturais, o que é um bônus a todos que experienciam isso. A coordenadora também qualifica a experiência como gratificante, pois vê "a internacionalização na universidade como um caminho para trocas de experiências no âmbito científico, político, cultural, pessoal, que trarão benefícios ímpares a todos os envolvidos nesse processo",

Assim como a coordenadora Laura, os professores também qualificaram o programa como desafiador e que exige muita responsabilidade, pois, como afirma $\mathrm{X}$, o programa requer uma formação acadêmica e linguística de alta qualidade dos docentes. Já Wali declarou que o desafio se dá na tentativa de proporcionar ao participante Revista X, v. 16, n. 6, p. 1510-1527, 2021. 
a capacidade de aplicar os conhecimentos assimilados durante as aulas em contextos reais de uso da língua. Já a professora Ana, por sua vez, afirma que estar no PFI é uma experiência "inexplicável" e que tem the proporcionado "um crescimento profissional muito grande e pessoal também [...] Estar com esses alunos, desafiá-los, me desafiar a cada encontro, a cada aula dada é tudo muito especial e muito significativo pra minha carreira profissional, sem dúvida".

Uma vez que os participantes qualificaram o programa como desafiador e até teceram elogios ao serem questionados sobre a influência do PFI na internacionalização da universidade, podemos entender que o programa tem cumprido esta função de forma satisfatória, tanto ao proporcionar vivências que objetivam a uma proficiência linguística dos participantes quanto ao oferecer editais e bolsas de estudo internacionais para os integrantes do PFI (o que, na visão de Ana, poderia ser mais intensificado).

\section{Pontos positivos e lacunares do PFI}

O último tópico que abordamos diz respeito aos pontos positivos e lacunares do Paraná Fala Inglês. Tanto professores quanto coordenadoras elencaram o espaço físico como um ponto a ser melhorado na IES em tela, visto que, durante as aulas presenciais, há atividades de interação entre professor x aluno e aluno x aluno, bem como atividades online. Porém, o espaço onde aconteciam os encontros, por conta da disposição dos móveis, dificultava a execução de tais atividades interativas. Ainda, explicam que, na IES em questão, não há um espaço próprio, exclusivo para as aulas do programa. Tal fato pode se dar devido à mudança da coordenação do PFI da primeira para a segunda fase (na primeira, a coordenação era de responsabilidade de professores do Instituto de Línguas; enquanto que, a partir da segunda fase, a coordenação passou a ser assumida por docentes do Departamento de Letras Modernas da universidade).

Ainda sobre os aspectos lacunares, mencionaram também a necessidade de melhoria na divulgação dos cursos, o teste de nivelamento aplicado aos alunos, o qual, na época, de acordo com alguns deles, não dimensionava a contento o nível de proficiência dos alunos. Por sua vez, Lia pontuou também as vagas remanescentes nas turmas, na época da geração dos dados. Para Laura, outros pontos lacunares do programa se referem à compra do material utilizado em algumas aulas por meio da plataforma e a falta de materiais que satisfaçam as necessidades de cursos específicos; além disso, ela também pontua questões referentes aos valores de recursos destinados a atividades específicas (e.g. locomoção para reuniões presenciais; bolsa). 
Como observamos, alguns dos pontos lacunares aqui pontuados trazem uma visão bastante local e particular de um determinado contexto no qual o programa está inserido. Podemos dizer, então, que algumas das lacunas aqui mencionadas são voltadas a particularidades do PFI na universidade em tela.

Em relação aos pontos positivos, Lia destacou o comprometimento e a organização da equipe, além da formação linguística e acadêmica dos docentes do PFI. Por sua vez, Laura ressaltou alguns pontos positivos que já foram mencionados em questões anteriores, como: impulso da internacionalização e editais de mobilidade acadêmica; parcerias que viabilizam a pesquisa no âmbito internacional e a troca de experiência. Além disso, mencionou a plataforma usada em alguns cursos do programa, a valorização da formação docente continuada e a ampliação de idiomas abrangidos pelo programa a partir do ano de 2018.

Os pontos positivos elencados pelos professores foram a distribuição da carga horária de trabalho, que viabiliza um bom planejamento das aulas, visto que privilegia o preparo de aula; a orientação das coordenadoras em relação aos planos de aulas e a pluralidade de cursos ofertados pelo PFI. Wali ainda salientou o número reduzido de alunos em cada turma. Já Ana, diferente de Wali e X, enalteceu a boa qualidade da plataforma utilizada nas aulas e também destacou o ensino linguístico e cultural. Em oposição a Ana, X apontou o valor da bolsa como um ponto positivo do PFI.

Como podemos observar deste item, os aspectos positivos se sobressaíram aos lacunares de acordo com as colocações dos integrantes do PFI. A formação linguística e acadêmica dos docentes se mostrou além do desejável e foi ressaltada pela coordenadora Lia. Laura enfatiza o papel do programa enquanto propulsor da internacionalização na universidade e pelos editais de mobilidade oferecidos, além de propiciar parcerias científicas internacionais. Ela ainda menciona a importância do programa na valorização da formação docente continuada. Entre os professores, a carga horária que favorece um bom planejamento das aulas foi destaque, bem como a orientação que receberam das coordenadoras. Ana relata que: “[...] esse projeto do governo tem ofertado aos alunos uma grande oportunidade, não só de expansão, de língua, não só de conhecimento, mas também de respeito cultural do outro, a conscientização, a sensibilização para uma outra língua. E por ser um projeto gratuito do governo, isso nos faz ainda mais motivados, porque de fato, isso é difícil de acontecer".

Com base na análise e discussão dos dados aqui apresentadas, entendemos que o PFI da IES em tela, de acordo com os relatos dos respondentes, vem cumprindo com seu objetivo de capacitar linguisticamente seus participantes e prepará-los para 
vivenciar o processo de internacionalização da universidade, nos mais diversos modos que esta pode ocorrer. Ainda, vislumbramos que esse tem se mostrado um contexto relevante e diferenciado para a formação docente continuada, aprendizagem conjunta e trabalho em equipe.

Sobre formação de professores em programas/contextos de internacionalização, pontuamos que, conforme mapeamento realizado por Molinari, Franco e Passoni (2020), principalmente no no contexto do programa Idioma sem Fronteiras (IsF), alguns trabalhos com esse foco (e.g. KIRSCH; SARMENTO, 2017; HOFFMAN; FÉLIX, 2016) se utilizam do referencial de comunidades de prática (e.g. WENGER, 1998) para tratar de aspectos que envolvem "colaboração, o compartilhamento e (re)construção coletiva de significados de grupos heterogêneos de professores" (p. 71). Tal perspectiva parece também dialogar com a experiência de formação docente continuada dos integrantes do PFI, representada em algumas das respostas ao questionário.

Sobre o contexto do IsF, Kirsch (2019) nos explica que esse também acabou sendo considerado como um outro contexto de prática de formação de professores: "a partir do ano de 2015 o IsF passa a ser tratado como um programa focado na formação de professores." (p.12). Por sua vez, Molinari, Franco e Passoni (2020, p. 74) acrescentam que a criação do IsF em 2012 não abordava a formação de professores com um de seus propósitos. Elas explicam que somente na segunda fase desse programa "[...] passam a ser colocadas em pauta as iniciativas desenvolvidas e necessárias para se alcançar o "fortalecimento das licenciaturas e a formação de professores de idiomas nas IES credenciadas ao Programa (Brasil, 2014, p. 14).” (MOLINARI, FRANCO E PASSONI, 2020, p. 74).

Conforme vislumbrado, os dois contextos aqui citados (PFI e IsF) no panorama de internacionalização, principalmente por trabalhar com a proficiência linguística da comunidade acadêmica, também são considerados como lócus de formação docente. Nesse sentido, Molinari, Franco e Passoni (2020) argumentam que, no resultado do mapeamento que realizaram, "é possível vislumbrarmos uma dualidade entre o ensino de língua inglesa e uma formação de professores no contexto da internacionalização que atenda tanto a fins práticos, como se volte a uma formação crítica" (p. 75). Defendem, então, que é tarefa dos cursos de formação de professores, configurados de várias formas ("graduações, pós-graduações ou mesmo ações de extensão ou demais cursos para professores já licenciados”), organizar propostas que desafiem o ensino apenas utilitarista da língua, planejando uma educação crítica e transformadora. 


\section{CONCLUSÃO}

Esta pesquisa teve como objetivo analisar a visão de coordenadoras e professores do Paraná Fala Inglês, em sua segunda fase, de uma universidade norte-paranaense. Para a geração dos dados, foram enviados a eles, em 2018, questionários de cunho dissertativo, os quais abordavam questões voltadas ao programa no processo de internacionalização acadêmica; às expectativas dos participantes e aos pontos positivos e lacunares do PFI.

De modo geral, a partir da análise e discussão dos dados, notou-se que, na visão das coordenadoras e dos professores, o programa tem contribuído com a internacionalização da IES por meio da oferta de cursos que capacitam linguisticamente a comunidade acadêmica e de editais de mobilidade. Em relação às expectativas de participação no PFI, elas se concretizaram, se mantiveram e/ou foram ressignificadas de forma positiva. Isso nos mostra que o programa também é um locus de trabalho impactante e gratificante para aqueles que fazem/fizeram parte dele. Ademais, mesmo havendo pontos lacunares, os aspectos positivos se sobressaíram.

Conclui-se, então, que, pela visão dos participantes, o programa tem caminhado para atingir seu objetivo primordial e tem se mostrado grandioso na capacitação linguística da comunidade acadêmica com vistas à internacionalização. No entanto, essa comunidade precisa estar mais consciente quanto à importância de uma língua estrangeira (LE) para o aprimoramento acadêmico, profissional e pessoal, para assim melhor usufruir dos cursos ofertados. Nesse sentido, enaltecendo a importância das LEs no cenário de internacionalização, Abreu Lima e Moraes Filho (2016) argumentam que, dentre muitos aspectos (e.g. definição de objetivos articulados com demandas educacionais e diretrizes nacionais e internacionais; investimento em infraestrutura e recursos humanos, uso de tecnologias de informação e comunicação), as questões linguísticas também estão abarcadas e subjacentes aos processos de internacionalização.

Por fim, observamos que a formação docente continuada dos profissionais pertencentes ao quadro do programa também merece destaque no contexto do PFI.

\section{REFERÊNCIAS}

ABREU-E-LIMA, D. M.; MORAES FILHO, W.B. Languages without Borders Program (LwB): buiding a Brazilian policy for teaching languages towards internationalization. In: FINARDI, K. R. (Org.). English in Brazil: views, policies and programs. Londrina: Eduel, 2016. 
ANDRÉ, M. E. D.A. Etnografia da prática escolar. São Paulo: Papirus, 1995.

BAUMVOL, L. K.; SARMENTO, S. A Internacionalização em casa e o uso de inglês como meio de instrução. Echoes, p. 65-82, 2016

BEELEN, J.; JONES, E. Redefining internationalization at home. In: CURAI, A, MATEI, L, PRICOPIE, R. (Org.). The European Higher Education Area: Between Critical Reflections and Future Policies. Dordrecht: Springer, 2015. p. 59-72

BORGES, E. F. V. B; MARSON, I. C. V. "Paraná Fala Inglês" na UEPG: experiência extensionista com foco na mobilidade internacional. Extensio: R. Eletr. De Extensão, Florianópolis, v. 12, n. 20, p. 73-89, 2015.

CASTRO, A. A; NETO, A. C. O ensino superior: a mobilidade estudantil como estratégia de internacionalização na América Latina. Revista Lusófona de Educação, Lisboa, n. 21, p. 69-96, 2012.

JORDÃO, C. M.; MARTINEZ, J. Z. Entre as aspas das fronteiras: internacionalização como prática agonística. In: ROCHA, C. H.; BRAGA, D. B.; CALDAS, R. R. (Org.). Políticas Linguísticas, ensino de línguas e formação docente: desafios em tempos de globalização e internacionalização. Campinas: Pontes Editores, 2015, p. 61-87.

KIRSCH, W. Processos de internacionalização e seus legados involuntários: o caso da formação de professores de inglês como língua adicional dos centros de língua inglesa do programa idiomas sem fronteiras. Revista Organon: Rio Grande do Sul, v. 34, n. 66, 2019. Disponível em <https://seer.ufrgs.br/organon/article/view/91293/54239> Acesso em 11 de set. de 2021.

MARRARA, J; RODRIGUES, J. A. Medidas de internacionalização e o uso de idiomas estrangeiros nos programas de pós-graduação brasileiros. RBPG, Brasília, v.6, n.11, p. 121-143, dez. 2009.

MOLINARI, A. C.; FRANCO, S.A. P.; PASSONI, T.P. Formação de professores de línguas em contexto de internacionalização. Revista NUPEM, Campo Mourão, v. 12, n. 26, p. 62-80, maio/ago. 2020.

PARANÁ FALA IDIOMAS. Cursos de Inglês. Disponível em: $<$ https://pfiuem.wixsite. com/pfiuem/ingles $>$. Acesso em 20 de fev. 2019.

PASSONI, T. P. O Programa Inglês sem Fronteiras como política linguística: um estudo sobre as ideologias da língua inglesa no âmbito da internacionalização do ensino superior brasileiro. 2018. 278 fls. Tese (Doutorado em Estudos da Linguagem) - Universidade Estadual de Londrina, 2018. 
PEREIRA, L.S.M.; SILVA, K.A.; GUIMARÃES, R. M. Internacionalização da educação como prática translíngue: parâmetros e proposições para a formação crítica de professores de línguas. Revista X, v.15, n.1, p. 202-226, 2020.

RIOS, E. S.; NOVELLI, J.; CALVO, L. C. S. (Org.). Paraná Fala Idiomas - Inglês: Pesquisas, práticas e desafios de uma política linguística de Estado. Campinas, SP : Pontes Editores, 2021.

RIOS, E. S. O Paraná Fala Idiomas: um programa estratégico da Superintendência Geral da Ciência, Tecnologia e Ensino Superior. In: RIOS, E. S.; NOVELLI, J.; CALVO, L. C. S. (Org.). Paraná Fala Idiomas - Inglês: Pesquisas, práticas e desafios de uma política linguística de Estado. Campinas, SP : Pontes Editores, 2021.

ROMÃO, J. E. "Epistemologia” Hegemônica e a Internacionalização da Educação Superior Brasileira. Pedagogia y Saberes, Universidad Pedagógica Nacional, Facultad de Educaciõn, n. 35, p. 55-65, 2011.

SECRETARIA DA CIÊNCIA, TECNOLOGIA E ENSINO SUPERIOR. Apresentação Programa Paraná Fala Inglês. Disponível em: < http://www.seti.pr.gov.br/ugf/programas/ paranafalaidiomas/apresentacao> Acesso em 20 de fev. 2019.

STALLIVIERI, L. O processo de internacionalização nas instituições de ensino superior. Educação Brasileira: revista do Conselho de Reitores das Universidades Brasileiras, Brasília, v. 24, n. 48, p. 35-57, 2002.

WENGER, E. Communities of practice: learning, meaning, and identity. New York: Cambridge University Press, 1998. 